\title{
Dose-response relationship between naloxone injections and intake of sucrose solution
}

\author{
MING-FUNG WU, MARCIA D. LIND, JUNE M. STAPLETON, and LARRY D. REID \\ Rensselaer Polytechnic Institute, Troy, New York 12181
}

\begin{abstract}
When individually housed rats are given, daily, a 1-h opportunity to drink a $10 \%$ solution of sucrose, they avidly take large amounts. When given naloxone, the prototypic antagonist of morphine-like effects, the intake of sucrose is attenuated. Doses as small as $.065 \mathrm{mg} / \mathrm{kg}$ reliably, but slightly, reduce intake and doses greater than $1.0 \mathrm{mg} / \mathrm{kg}$ dramatically reduce intake.
\end{abstract}

Without food deprivation, rats readily take sweetened solutions and, in general, have a strong preference for sweet foods. Individually housed male rats will take, for example, about $20 \mathrm{ml}$ of a $10 \%$ sucrose solution when it is presented daily for $1 \mathrm{~h}$ and when they have had standard laboratory food and water always available. When deprived of food, rats will take more sucrose solution than when not deprived, but privation is not a prerequisite for avid intake of sucrose solutions.

This brief report concerns observations following those reported in Ostrowski, Foley, Lind, and Reid (1980) and Stapleton, Ostrowski, Merriman, Lind, and Reid (1979). In nondeprived and deprived rats, naloxone was found to dramatically reduce rats' intake of a $10 \%$ sucrose solution. It is inferred that the effects of naloxone in subjects having never received exogenous opioids reflect antagonism of endorphinergic systems (Goldstein, 1978).

Naloxone reduces intake of food and water in deprived rats (Holtzman, 1974, 1975). In a test of the idea that deprivation was a prerequisite for naloxone to have an effect on consummatory behavior, Stapleton et al. (1979) gave naloxone $(10 \mathrm{mg} / \mathrm{kg})$ to nondeprived rats taking sucrose solutions and found that naloxone dramatically suppressed the intake of sucrose solution. Naloxone $(2 \mathrm{mg} / \mathrm{kg})$ also reduces sucrose intake in 24- and 48-h food-deprived rats (Ostrowski et al., 1980). Perhaps, relatedly, naloxone suppresses food intake in response to glucoprivation induced by injections of 2-deoxy-d-glucose and insulin (Lowy, Maickel, \& Yim, 1980; Ostrowski, Rowland, Foley, Nelson, \& Reid, in press). These observations support the idea that endorphinergic units are part of the system regulating blood sugar levels and the behavior of intake of sugars.

Naloxone could have its suppressive effects because it antagonizes endorphinergic controls for the regulation of nutrients or because it causes the rats to be sick or to suffer a general malaise. Naloxone effects have been shown to establish a conditioned flavor aversion when naloxone injections are used as the putative unconditioned stimulus in the now classical conditioned taste aversion paradigm (Stolerman, Pilcher, \& D'Mello, 1978). It was found, however, that the ability of nalox- one to suppress sucrose intake did not covary with naloxone's capability to establish a conditioned flavor aversion (Ostrowski et al., 1980), and this leads to the conclusion that the processes associated with naloxone's ability to establish a conditioned flavor aversion can account for little, if any, of the effect of naloxone on suppression of sucrose intake. The conclusion that the suppressive effects of naloxone on sugar intake are not related to naloxone's ability to establish a conditioned taste aversion indirectly supports the hypothesis of an endorphinergic control mechanism in the regulation of ingestion because it eliminates one major alternative explanation.

We now report the results of tests of the effects of various doses of naloxone on the intake of sucrose solutions. Naloxone, in remarkably small doses, does suppress intake of sucrose solution in rats not subjected to food or water deprivation.

\section{METHOD}

The subjects were 10 experimentally naive male rats (SpragueDawley descended, Taconic Farms, Germantown, New York) weighing $220-300 \mathrm{~g}$ at the start of the procedures. They were housed individually in standard laboratory cages with food always available and water always available except when the sucrose solution was presented. The cages were in a colony room maintained on a 12-h light, 12-h dim light cycle (lights fully on beginning at 10:00 p.m.).

Testing for intake of sucrose solution took place while rats were in their home cages, during the dim light phase of the light cycle. Sucrose solutions were presented in bottles equipped with ball-point sipping tubes. The bottles were weighed before and after presentation, to the nearest $.1 \mathrm{~g}$, to determine the amount of fluid consumed.

Rats were given the opportunity to take sucrose solution daily for $1 \mathrm{~h} /$ day. The sucrose solution was $10 \%$ sucrose (weight/ volume). Subjects' water bottles were removed from their cages and replaced by the bottles containing the sucrose solution. Rats were given the opportunity to take sucrose solutions for 14 days before a regimen of injections was given, so that their daily intakes would be stable across daily tests.

After the 14-day stabilization period and across the next 3 days, all rats were administered physiological saline injections $(1 \mathrm{ml} / \mathrm{kg}) 15 \mathrm{~min}$ before presentation of sucrose solutions. On the next day, each rat received an injection of naloxone before presentation of sucrose solution. Then there were 3 more days of saline injections, followed by 1 day of naloxone injections. 
This cycle of 3 days of saline injections followed by 1 day of naloxone injections continued until each rat received each dose of naloxone before a presentation of sucrose solution.

The doses of naloxone $\mathrm{HCl}$ were $.0625, .0125, .25, .5,1.0$, $2.0,5.0,10.0$, and $20.0 \mathrm{mg} / \mathrm{kg}$ (doses expressed in terms of the salt). After random assignment, one half of the rats received, on the schedules of test days, the naloxone doses in an ascending order of magnitude and the other half received the doses in a descending order. Volumes of all injections were $1 \mathrm{ml} / \mathrm{kg}$, and all injections were given subcutaneously. Consequently, there were two groups of subjects (one getting drugs in ascending order and one in the descending order) and nine doses of naloxone. We used the measures of the day before injection of naloxone as the best index of what rats would take under saline injections. Therefore, the experimental design conforms to a 2 by 2 by 9 analysis of variance having repeated measures and factors of two groups (ascending or descending order of size of naloxone injections), two kinds of injections (saline or naloxone), and nine doses.

\section{RESULTS}

The scores for sucrose consumption after various doses of naloxone, as well as those from the preceding day after saline injections, were submitted to a 2 by 2 by 9 ANOVA for repeated measures. This ANOVA yielded $F(1,8)=177.24(p<.001)$ for the factor associated with naloxone-saline injections, $F(8,64)=9.24(\mathrm{p}<.001)$ for the factor associated with the various doses of naloxone, and $F(8,64)=9.76(p<.001)$ for the Naloxone-Saline by Dose interaction. The factor associated with order of dosing (groups) was not a reliable source of variance. Also, no other factor represented a reliable source of variance. Using $t$ tests for correlated measures to compare responding under saline injections with those under a dose of naloxone, it can be concluded that naloxone produced reliable decreases in intake at all doses $[\mathrm{ts}(9) \geqslant 1.8$, ps $<.03]$. Trend analysis showed that there are linear and quadratic components in the dose-related suppression of consumption $[F(1,72)=86.7, p<.001$, and $F(1,72)=6.3$, $\mathrm{p}<.01$, respectively]

Figure 1 summarizes the results by presenting mean difference scores. The difference scores were derived by subtracting the score of the preceding saline day from the score for a naloxone dose. Doses greater than $1 \mathrm{mg} / \mathrm{kg}$ of naloxone do not appear to enlarge, but slightly, the effect.

\section{DISCUSSION}

Subsequent to the experiment reported here, other rats were tested for opioid effects on intake of $10 \%$ sucrose solutions. Using a very similar regimen of testing, it was found that doses of 50 micrograms and larger of naloxone intracerebroventricularly (icv) into one lateral ventricle reduced intake somewhat. For example, a dose of 200 micrograms of naloxone icv produced only an 8 -g difference score (compared with a $1-$ or $10-\mathrm{mg} / \mathrm{kg}$ subcutaneous (sc) dose producing 12- to $14 \mathrm{~g}$ reduction). Since such large icv doses are necessary, little can be concluded concerning whether naloxone might have central neural effects specifically associated with reduction of sucrose intake. Also, to test adequately for central effects, it is probably necessary to

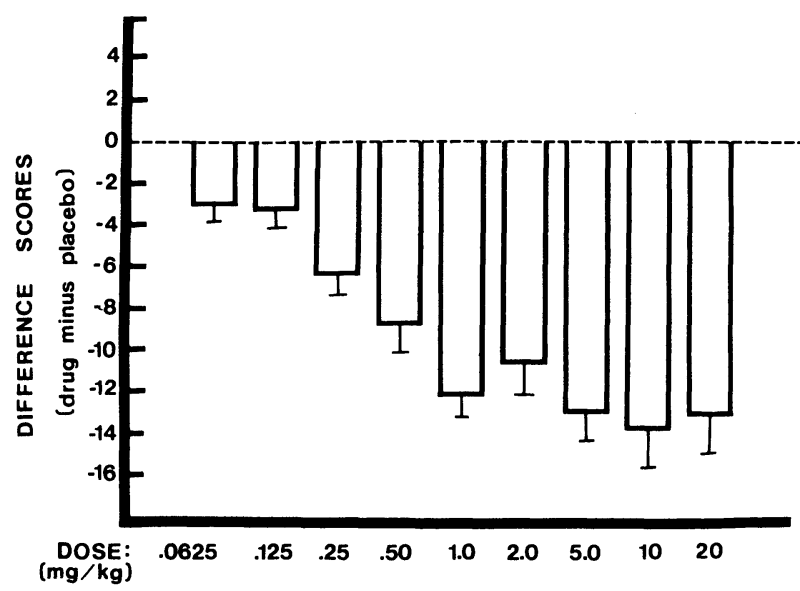

Figure 1. Mean difference scores derived by subtracting the amount of sucrose solution ( $10 \%$ sucrose) taken on day before naloxone injections from amount taken on day of injection for each dose of naloxone $\mathrm{HCl}$ tested. Negative scores, therefore, indicate a reduction in intake compared with placebo injection. Also indicated are standard errors of the difference scores.

use bilateral infusions and an opioid antagonist that is less lipophilic than naloxone.

With similar procedures, Win 44,441 , another opioid antagonist, produced only slight (about 2-g) suppression in intake of sucrose solution at a dose of $10 \mathrm{mg} / \mathrm{kg}$, sc, and nalorphine, a mixed agonist-antagonist, at $10 \mathrm{mg} / \mathrm{kg}$, sc, produced no reliable suppression of intake. Both of these agents, at these doses, suppressed intake of water among water-deprived rats (Ostrowski et al., in press). These preliminary observations lead us to suggest that the antagonist suppression of sugar-water intake may be due to a constellation of opioid processes different from those to which antagonist suppression of water intake is due (see Brown \& Holtzman, 1980, for a profile of antagonist effects on water intake).

The issues of whether naloxone is acting centrally and whether there is pharmacological specificity with respect to opioid antagonists' effects on intake of sucrose solution are left open. There is little doubt, however, that naloxone dramatically reduces intake of sucrose in both food-deprived and nondeprived rats (Ostrowski et al., 1980; Stapleton et al., 1979; and this report). The fact that naloxone has its effects on reducing sucrose intake in nondeprived rats leads one to conclude that naloxone can reduce feeding without the stress of food deprivation (see Lowy et al., 1980, for the suggestion that naloxone is related to eating associated with stress).

There are now two lines of evidence to counter the idea that naloxone reduces intake of nutrients because naloxone itself sets up a mild illness or malaise. There is no apparent relationship between the ability of large doses of naloxone to sustain a conditioned flavor aversion and ability of naloxone to suppress intake of sucrose (Ostrowski et al., 1980). The effective doses found in this demonstration are below those that produce any signs of a conditioned aversion. Naloxone may, however, suppress sugar-water intake by interfering with the processing of sugar and, thereby, produce changes that, in time, make further intake of sugar an aversive event. It is likely that opioids, both exogenous and endogenous, modify functioning of islet cells of the pancreas (Ipp, Dobbs, \& Unger, 1978). Sugar, even a small amount, under the influence of naloxone may not be palatable.

Research across the last few years has led to the conclusion that an endorphinergic system is part of regulatory processes germane to maintaining energy balance. The extensive knowl- 
edge already accumulated concerning regulation of eating needs to be evaluated again in light of the basic fact that naloxone dramatically reduces intake of nutrients, especially sweet solutions, in nondeprived rats at remarkably small doses.

\section{REFERENCES}

Brown, D. R., \& Holtzman, S. G. Evidence that opiate receptors mediate suppression of hypertonic saline-induced drinking in the mouse by narcotic antagonists. Life Sciences, 1980, 26, 1543-1550.

Goldste in, A. Opiate receptors and opioid peptides. In M. A. Lipton, A. Dimascio, \& K. F. Kellman (Eds.), Psychopharmacology: A generation of progress. New York: Raven Press, 1978.

Holtzman, S. G. Behavioral effects of separate and combined administration of naloxone and d-amphetamine. Journal of Pharmacology and Experimental Therapeutics, 1974, 189, 51-60.

Holtzman, S. G. Effects of narcotic antagonists on fluid intake in the rat. Life Sciences, 1975, 16, 1465-1470.
IPP, E., DobBs, R., \& Unger, R. H. Morphine and $\beta$-endorphin influence the secretion of the endocrine pancreas. Nature, 1978, 276, 190-191.

LowY, M. T., Maickel, R. P. , \& YıM, K. W. Naloxone reduction of stress-related feeding. Life Sciences, 1980, 26, 2113-2118.

Ostrowski, N. L., Foley, T. L., Lind, M. D., \& Reid, L. D. Naloxone reduces fluid intake: Effects of water and food deprivation. Pharmacology, Biochemistry and Behavior, 1980, 12, 431-435.

Ostrowski, N. L., Rowland, N., Foley, T. L., Nelson, J. L. \& REID, L. D. Morphine antagonists and consummatory behavior. Pharmacology, Biochemistry and Behavior, in press.

Stapleton, J. M., Ostrowski, N. L., Merriman, V. J., Lind, M. D., \& REID, L. D. Naloxone reduces fluid consumption in water-deprived and nondeprived rats. Bulletin of the Psychonomic Society, 1979, 13, 237-239.

Stole rman, I. P., Pilcher, C. W. T., \& D'Mello, G. D. Stereospecific aversive property of narcotic antagonists in morphine-free rats. Life Sciences, 1978, 22, 1755-1762.

(Received for publication January 20, 1981.) 